\title{
Transitive inference in pigeons: Simplified procedures and a test of value transfer theory
}

\author{
JANICE N. STEIRN and JANICE E. WEAVER \\ Georgia Southern University, Statesboro, Georgia \\ and \\ THOMAS R. ZENTALL \\ University of Kentucky, Lexington, Kentucky
}

\begin{abstract}
Minimal procedures for the demonstration of transitive inference (TI) in animals have involved the training of four simultaneous discriminations: for example, $\mathrm{A}+\mathrm{B}-, \mathrm{B}+\mathrm{C}-, \mathrm{C}+\mathrm{D}-$, and $\mathrm{D}+\mathrm{E}-$, followed by the demonstration of a preference for $B$ over $D$ on test trials. In Experiment 1 , we found that $\mathrm{TI}$ in pigeons can be found with successive training involving $\mathrm{A}+\mathrm{B}-, \mathrm{B}+\mathrm{C}-, \mathrm{A}+\mathrm{C}-, \mathrm{C}+\mathrm{D}-$, $\mathrm{D}+\mathrm{E}-, \mathrm{C}+\mathrm{E}-$, and $\mathrm{A}+\mathrm{E}-$. In Experiment 2, we found that demonstration of TI did not require inclusion of experience with the nonadjacent stimulus pairs $(\mathrm{A}+\mathrm{C}-, \mathrm{C}+\mathrm{E}-, \mathrm{A}+\mathrm{E}-)$. Experiment 3 provided a test of value transfer theory (VTT; Fersen, Wynne, Delius, \& Staddon, 1991). When pigeons were trained with stimulus pairs that did not permit the transitive ordering of stimuli, but did permit the differential transfer of value (e.g., $A+B-, C-E+, C+D-, \& A+E-$ ), preference for $B$ over $D$ was still found. Analyses of the relation between direct experiences with reinforced and nonreinforced responding and stimulus preferences on test trials failed to support a reinforcement-history account of TI.
\end{abstract}

In a human transitive inference (TI) task, a subject might be given two premises - for example, "Pam is shorter than Sally" and "Sally is shorter than Paula." Evidence of transitive inference is the ability to identify "Who is shorter, Pam or Paula?" Humans can often respond correctly, despite the fact that information about the relative height of Pam and Paula was never directly presented.

Piaget $(1928,1955)$ believed that successful performance on such transitive inference tasks is evidence for the ability to use rules of inferential logic. Piaget found that only children who had reached the stage of concrete operations (approximately 7 years of age) could respond correctly on this task. Bryant and Trabasso (1971), however, found that preoperational children (below the age of 7) could successfully perform the TI task, if their memory for presented information (i.e., all of the stimulus pairs presented in training) was intact.

McGonigle and Chalmers (1977) were the first to examine TI performance in nonhumans. They developed a method of presenting successive pairs of stimuli to squirrel monkeys in the form of simple simultaneous dis-

Data collection for Experiment 3 was supported by a faculty development grant from Georgia Southern University to the first author. Preparation of this manuscript was supported by National Science Foundation Grant BSN-9019080 and National Institute of Mental Health Grant MH45979 to the third author. Correspondence should be addressed to J. N. Steirn, Department of Psychology, Landrum Box 8041, Georgia Southern University, Statesboro, GA 30460.

-Accepted by previous editor, Vincent M. LoLordo criminations. In their procedure, Stimulus A and Stimulus B were presented simulianeously; the choice of Stimulus A was reinforced, whereas the choice of $B$ was $\operatorname{not}($ i.e., $A+B-$ ). Then, Stimulus $B$ and Stimulus $C$ were presented, and the choice of $B$ was reinforced $(B+C-)$. In a similar manner, Stimulus Pairs $\mathrm{C}+\mathrm{D}-$ and $\mathrm{D}+\mathrm{E}-$ were presented. Such training can be depicted as a fiveterm A-E series, with Stimuli A and E as endpoints, each with a unique reinforcement history. The purpose of the five-term series is to allow the test pair to be drawn from nonadjacent, nonendpoint stimuli (BD) that have been similarly associated with reinforcement and nonreinforcement. When McGonigle and Chalmers presented their subjects with the BD test pair, Stimulus B was consistently selected.

The use of the five-term (minimum) series has been adopted in studies of TI in humans (e.g., Chalmers \& McGonigle, 1984; Trabasso \& Riley, 1975) as well as nonhumans (e.g., Davis, 1992b, with rats; Fersen, Wynne, Delius, \& Staddon, 1991, with pigeons; Gillan, 1981, with chimpanzees; McGonigle \& Chalmers, 1977, with monkeys).

Although successful performance of the TI task has been found in a variety of species, the processes underlying this performance are not clearly understood. In addition to the suggestion that findings of TI indicate either the development of an internal representation of a linear stimulus series or the integration of a set of logical propositions, two noncognitive accounts of TI in animals have recently been proposed (Couvillon \& Bitterman, 1992; Fersen et al., 1991). The first noncognitive ac- 
count of TI is based on the direct history of reinforcement associated with each of the test stimuli. Although this theory has been presented in the context of various stochastic linear-operator models (Couvillon \& Bitterman, 1992; Wynne, Fersen, \& Staddon, 1992), it can be somewhat simplified as follows: Although the nonendpoints of the A-E series have each been associated with reinforced as well as nonreinforced responding, reinforcement histories with those central stimuli are not likely to be identical. In fact, experience with (i.e., responding to) $\mathrm{B}-$, presented in the context of $\mathrm{A}+$ (which is never associated with nonreinforced responding) is likely to be somewhat less than experience with $\mathrm{D}-$, presented in the context of $\mathrm{C}+$ (which is also associated with nonreinforced responding in the context of $\mathrm{B}+$ ). Thus, less experience with $\mathrm{B}-$ than with $\mathrm{D}-$ could account for a preference for $\mathrm{B}-$ in the absence of relational learning.

The second noncognitive account of TI involves the transfer of associative value from one member of a stimulus pair to the other (Fersen et al., 1991). According to this value transfer theory (VTT), the member of each stimulus pair associated with nonreinforced responding acquires secondary positive value from the positive member of the pair. According to Fersen et al., the extent of the value that transfers will depend on the value of the positive member of each pair. In the case of $B$ - presented in the context of $\mathrm{A}+$ (a stimulus never associated with nonreinforced responding), the value transferred should be relatively high. However, in the case of $\mathrm{D}-$, presented in the context of $\mathrm{C}+$ (a stimulus also associated with nonreinforced responding in the context of $\mathrm{B}+$ ), the value transferred should be somewhat less. According to Fersen et al., this discrepancy in value transferred is responsible for preference of B over D on test trials.

The present experiments were conducted to establish a procedure that would produce the typically found TI transfer performance in pigeons and to evaluate explanations of the TI effect.

\section{EXPERIMENT 1}

Transitive inference studies with animals all have some procedures in common (e.g., the use of arbitrary stimuli and a five-item series); however, other aspects of the animal training procedures have varied widely, resulting in differences in training performance and training time required. For example, Fersen et al. (1991) trained their pigeons on all four training pairs $(\mathrm{A}+\mathrm{B}-, \mathrm{B}+\mathrm{C}-, \mathrm{C}+\mathrm{D}-$, $\mathrm{D}+\mathrm{E}-$ ) concurrently. Because four pairs were to be learned simultaneously, training procedures were used to encourage good performance on the training pairs (the negative member of each pair was faded in during initial training, and a correction procedure was used). Despite these measures, however, only 4 of 6 pigeons acquired the task to a criterion of $80 \%$ correct within 125 training sessions (with 40 trials, plus correction trials, per session). The 4 pigeons that were tested with the BD pair showed high levels of performance (choice of the $B$ stimulus). Because of the necessary extended training and the failure of some of the subjects to complete training, the Fersen et al. procedure produces an unwieldy measure of experience with the various training stimuli.

An alternative procedure has been developed by Davis (1992a, 1992b). Davis trained rats to discriminate pairs of olfactory stimuli, with each pair presented alone within a block of training sessions (i.e., pairs were presented successively). Davis included extra training pairs in his procedure to encourage the development of transitive relations. He trained his rats successively on the following pairs: $\mathrm{AB}, \mathrm{BC}, \mathrm{AC}, \mathrm{CD}, \mathrm{DE}, \mathrm{CE}, \mathrm{AE}$, and then tested them on the $B D$ pair. Davis reported that training proceeded rapidly and that good evidence for TI was found. Davis's procedure may be useful in testing theories based on relative reinforcement histories, because acquisition of the training pairs is considerably faster than acquisition with the more typical concurrent training procedures used by others (e.g., Fersen et al., 1991).

In Experiment 1, we used Davis's (1992b) proceduresuccessive presentations of stimulus pairs-to determine whether, under these conditions, TI performance similar to that found by Fersen et al. (1991) could be obtained with pigeons. With this successive procedure, a single stimulus pair was presented for a block of trials until a performance criterion was reached. Then training began on the next stimulus pair with no further training on the earlier pair. Training involved the four training pairs $(A B, B C, C D, D E)$, as well as the additional pairs used by Davis (AC, CE, and $\mathrm{AE}$ ).

\section{Method}

\section{Subjects}

The subjects were 8 mixed-sex, White Carneaux pigeons, obtained as retired breeders ( $5-8$ years old) from Palmetto Pigeon Plant, Sumter, SC. The pigeons were caged individually with grit and water continually available in the home cage. They were maintained at $80 \%$ of their free-feeding body weights throughout the experiment. The colony room was on a 12:12-h, light:dark cycle.

All the pigeons had previously served in unrelated studies involving the delayed-matching-to-sample task, as well as in a pilot for the current study. In the pilot study, hue stimuli were presented in premise pairs so that Pair BC was introduced following acquisition of Pair $\mathrm{AB}$, with continued training on $\mathrm{AB}$. Following acquisition of the discrimination on Pair $B C$, Pair $C D$ was introduced, with continued training on $\mathrm{AB}$ and $\mathrm{BC}$. In the final training phase, Pair DE was introduced, with continued training on $A B$, $B C$, and $C D$. As additional pairs were added, performance on previously acquired pairs tended to decrease. None of the pigeons succeeded in maintaining performance above $80 \%$ correct on all premise pairs concurrently.

\section{Apparatus}

The experiment was conducted in a BRS/LVE (Laurel, MD) pigeon test chamber with a Model PIP-016 three-key response panel. The test chamber measured 30 (front to back) $\times 36$ (across the response panel) $\times 36 \mathrm{~cm}$ (high). The three circular response keys $(2.5 \mathrm{~cm}$ diameter) were centered horizontally on the intelligence panel, $10 \mathrm{~cm}$ from the top of the panel, and were spaced $8.5 \mathrm{~cm}$ apart, center to center. Only the center and right keys were used. Behind each response key was a 12-stimulus inline projector (Industrial Electronic Engineering, Van Nuys, CA with General Electric No. 1820 lamps) that projected red (A), yellow (B),
} 
white (C), blue (D), and green (E) hues. A rear-mounted grain feeder was centered horizontally on the intelligence panel. When operated, the feeder was accessible through a $5.0 \times 5.5 \mathrm{~cm}$ aperture, the bottom of which was $9 \mathrm{~cm}$ from the mesh floor of the chamber. Reinforcement consisted of 1.5-sec access to Purina Pigeon Grains. A shielded houselight located $3 \mathrm{~cm}$ from the top of the panel, above the center response key, provided general illumination for the chamber. White noise at $72 \mathrm{~dB}$ and an exhaust fan mounted on the outside of the chamber masked extraneous noise.

\section{Procedure}

The pigeons were randomly assigned to one of two groups $(n=$ 4 each), balanced for the reinforcement contingency to be in effect in the succeeding phases. For Group $\mathrm{A}+$, the first member denoted in the premise pair was positive in the simultaneous discrimination (i.e., $\mathrm{A}+\mathrm{B}-, \mathrm{B}+\mathrm{C}-, \mathrm{C}+\mathrm{D}-, \mathrm{D}+\mathrm{E}-$ ). For Group $\mathrm{A}-$, the second member of the pair was positive (i.e., $\mathrm{A}-\mathrm{B}+, \mathrm{B}-\mathrm{C}+$, $\mathrm{C}-\mathrm{D}+, \mathrm{D}-\mathrm{E}+$ ).

Phase 1. The stimuli from the first premise pair (A and B) were presented concurrently on the center and right response keys, with position balanced across the 96 trials of the session and with the constraint that the same position could be correct for no more than three consecutive trials. Five consecutive responses to either stimulus resulted in termination of both stimuli and the initiation of a 10-sec intertrial interval (ITI), with the houselight illuminated. If the correct stimulus was chosen (A for pigeons in Group $\mathrm{A}+, \mathrm{B}$ for those in Group $\mathrm{A}-$ ), reinforcement was delivered during the first $1.5 \mathrm{sec}$ of the ITI.

Each pigeon remained on Phase 1 for a minimum of three sessions and until criterion was reached (at least $90 \%$ correct for two consecutive sessions). The pigeon then advanced to Phase 2 .

Phases 2-7. All conditions of stimulus presentation as well as the performance criteria were the same as those in Phase 1. The stimuli presented in each phase are presented in Table 1.

Test. On the day following completion of Phase 7 , each pigeon was tested for a single session of 96 trials with the BD stimulus pair. Stimulus choice was reinforced nondifferentially so that on a random $50 \%$ of the trials $\mathrm{B}$ was defined as correct, and on the remaining trials $\mathrm{D}$ was correct.

\section{Results and Discussion}

\section{Training}

Acquisition of the simultaneous discriminations was rapid, requiring a mean of only 2.2 sessions to criterion for each discrimination. The rate of acquisition appeared to be affected by whether the former $\mathrm{S}+$ became an $\mathrm{S}-$ or

\section{Table 1}

Design of Experiments

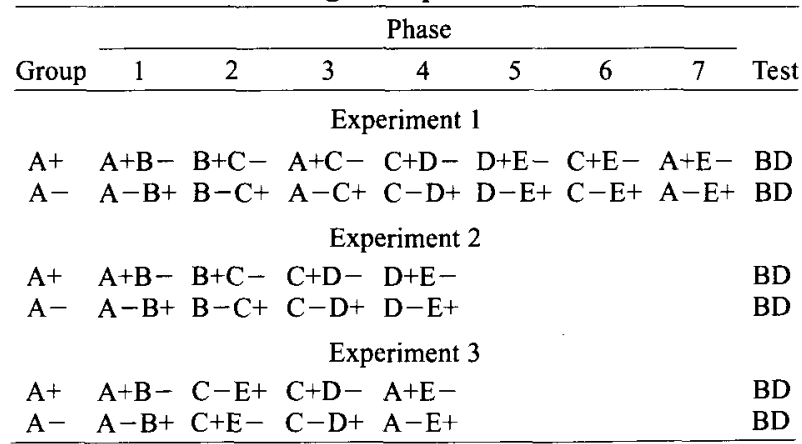

Note-A, red; B, yellow; C, white; D, blue; E, green. One member of each discrimination is associated with reinforced $(+)$ and nonreinforced (-) responding. BD test involves nondifferential reinforcement.
Table 2

Sessions to Criterion for Each Group in Each Phase of Training

\begin{tabular}{|c|c|c|c|c|c|c|c|}
\hline \multirow[b]{4}{*}{ Group } & \multicolumn{7}{|c|}{ Experiment 1: Phase } \\
\hline & 1 & 2 & 3 & 4 & 5 & 6 & 7 \\
\hline & \multicolumn{7}{|c|}{ Stimulus Pair } \\
\hline & $\mathrm{AB}$ & $\mathrm{BC}$ & $\mathrm{AC}$ & $\mathrm{CD}$ & $\mathrm{DE}$ & $\mathrm{CE}$ & $\mathrm{AE}$ \\
\hline At & 2.2 & 2.0 & 2.0 & 2.2 & 2.0 & 2.0 & 2.0 \\
\hline \multirow[t]{5}{*}{$A-$} & 2.0 & 2.8 & 2.0 & 2.5 & 3.0 & 2.5 & 2.0 \\
\hline & & \multicolumn{6}{|c|}{ Experiment 2: Phase } \\
\hline & & 1 & 2 & & 3 & & 4 \\
\hline & & \multicolumn{6}{|c|}{ Stimulus Pair } \\
\hline & & $\mathrm{AB}$ & $\mathrm{BC}$ & & $\mathrm{CD}$ & & $\mathrm{DF}$ \\
\hline $\mathrm{A}+$ & & 2.5 & 3.0 & & 3.5 & & 2.5 \\
\hline \multirow[t]{5}{*}{$\mathrm{A}-$} & & 3.0 & 3.0 & & 3.0 & & 3.2 \\
\hline & & \multicolumn{6}{|c|}{ Experiment 3: Phase } \\
\hline & & 1 & 2 & & 3 & & 4 \\
\hline & & \multicolumn{6}{|c|}{ Stimulus Pair } \\
\hline & & $\mathrm{AB}$ & $\mathrm{CE}$ & & $\mathrm{CD}$ & & $\mathrm{AE}$ \\
\hline At & & 2.5 & 2.8 & & 3.0 & & 2.2 \\
\hline$A-$ & & 2.8 & 2.0 & & 3.2 & & 2.0 \\
\hline
\end{tabular}

vice versa. A two-way mixed analysis of variance (ANOVA) was performed on the sessions-to-criterion data for the two groups (A+vs. $\mathrm{A}-$ ) across the seven training phases. The .05 level of significance was used here and in all subsequent analyses. The two groups differed significantly in the number of sessions to criterion across training phases $[M \mathrm{~s}=2.1$ and 2.4 for Groups $\mathrm{A}+$ and $\mathrm{A}-$, respectively; see Table $2 ; F(1,6)=10.56]$. Although the effect of phase was not significant $[F(6,36)=2.05]$, there was a significant groups $\times$ phase interaction $[F(6,36)=$ 2.68]. Sessions to criterion varied little across phases for Group A+, but varied substantially across phases for Group A-. Specifically, on Phases $2(\mathrm{~B}-\mathrm{C}+)$ and 5 $(D-E+)$, Group $A-$ showed an increase in sessions to criterion.

To further examine the differences in performance between groups in acquisition, first-session performance was examined for each group on each phase of training. These data appear in Table 3.

A two-way mixed ANOVA was conducted on performance on the first session of each phase, between groups and across phases. Again, there was a significant difference in performance between groups [mean performance $=97.8 \%$ and $88.7 \%$ for Groups $\mathrm{A}+$ and $\mathrm{A}-$, respectively; $F(1,6)=27.25$ ] and a significant group $\times$ phase interaction $[F(6,36)=8.72]$. Additionally, there was a significant difference in performance among phases $[F(6,36)=4.14]$. As can be seen in Table 3, performance on the first session of each phase was consistently high for Group A+, but varied for Group A-. This difference in initial difficulty of stimulus pairs may be related to the association of one member of the new pair with either nonreinforcement (in Group $\mathrm{A}^{+}$) or reinforcement (in Group A-) in the immediately preceding phase. For example, in Phases 1 and 2, Group A+ received 
Table 3

First-Session Accuracy (Mean Percentage Correct) for Each Group in Each Phase of Training

\begin{tabular}{|c|c|c|c|c|c|c|c|c|}
\hline \multirow[b]{4}{*}{ Group } & \multicolumn{7}{|c|}{ Experiment 1: Phase } & \multirow[b]{2}{*}{ Test } \\
\hline & 1 & 2 & 3 & 4 & 5 & 6 & 7 & \\
\hline & \multicolumn{7}{|c|}{ Stimulus Pair } & \\
\hline & $\mathrm{AB}$ & $\mathrm{BC}$ & $\mathrm{AC}$ & $\mathrm{CD}$ & $\mathrm{DE}$ & $\mathrm{CE}$ & $\mathrm{AE}$ & $\mathrm{BD}$ \\
\hline $\mathrm{A}+$ & 95.8 & 93.5 & 100.0 & 96.0 & 99.5 & 100.0 & 100.0 & 89.6 \\
\hline \multirow[t]{5}{*}{$A-$} & 100.0 & 82.0 & 100.0 & 83.8 & 67.0 & 85.5 & 99.5 & 85.4 \\
\hline & \multicolumn{7}{|c|}{ Experiment 2: Phase } & \\
\hline & \multirow{2}{*}{\multicolumn{2}{|c|}{1}} & 2 & & 3 & 4 & & Test \\
\hline & & & \multicolumn{5}{|c|}{ Stimulus Pair } & \\
\hline & & $\mathrm{AB}$ & $\mathrm{BC}$ & & $\mathrm{CD}$ & $\mathrm{DE}$ & & $\mathrm{BD}$ \\
\hline \multirow{6}{*}{$\begin{array}{l}\text { At } \\
\text { A- }\end{array}$} & & 36.0 & 65.5 & & 84.0 & 72.0 & & 82.3 \\
\hline & & 76.8 & 68.8 & & 66.8 & 60.5 & & 87.5 \\
\hline & & & \multicolumn{5}{|c|}{ Experiment 3: Phase } & \\
\hline & & 1 & 2 & & 3 & 4 & & Test \\
\hline & & & \multicolumn{5}{|c|}{ Stimulus Pair } & \\
\hline & & $\mathrm{AB}$ & $\mathrm{CE}$ & & $\mathrm{CD}$ & $\mathrm{AE}$ & & $\mathrm{BD}$ \\
\hline$A+$ & & 31.0 & 80.5 & & 34.2 & 97.5 & & $\overline{93.8}$ \\
\hline A- & & 1.0 & 92.8 & & 26.5 & 98.8 & & 91.7 \\
\hline
\end{tabular}

$\mathrm{A}+\mathrm{B}-$ and $\mathrm{B}+\mathrm{C}-$, respectively. In Phase 2 , Stimulus $\mathrm{C}$ was novel, relative to Stimulus B. Even though $B$ had been associated with nonreinforcement in Phase 1, the pigeons may have been more likely to peck the more familiar B than the novel $\mathrm{C}$. Conversely, Group A- received $\mathrm{A}-\mathrm{B}+$ and $\mathrm{B}-\mathrm{C}+$ in Phases 1 and 2, respectively. Again, $C$ was novel relative to $B$; however, in this case, B was previously associated with reinforcement, and the pigeons had already established a pattern of responding to $B$. The data indicate that it may be more difficult to abandon responding to a stimulus previously associated with reinforced responding and respond to a relatively novel stimulus than it is to begin responding to a stimulus previously associated with nonreinforced responding when forced to choose between this familiar stimulus and a relatively novel stimulus.

It should be recalled that all the pigeons had served in a pilot study in which they received these same stimuli, but they were trained on all pairs (i.e., $\mathrm{AB}, \mathrm{BC}, \mathrm{CD}$, and DE) simultaneously. Thus, these pairs had been experienced earlier. On the other hand, Pairs AC, CE, and AE had not been presented during the pilot study. Performance in both groups was high on these pairs, despite their novelty. Although high initial performance on these pairs may be indicative of the use of a mediational process related to transitive inference, a more parsimonious explanation is that, in each of these pairs, one of the stimuli represents an endpoint (see Bryant \& Trabasso, 1971). That is, for Group A+, Stimulus A had never been associated with nonreinforced responding, whereas for Group A-, Stimulus A had never been associated with reinforced responding. Similarly, for Group A+, Stimulus $E$ had never been associated with reinforced responding, whereas for Group A-, Stimulus E had never been associated with nonreinforced responding. This bias is further exacerbated in the AE pair, in which both endpoints are represented. Given the overall difference in difficulty on the first session of new phases for Group A-, one might expect the endpoints to have had less of an effect in determining performance on these novel pairs, and indeed, as can be seen in Table 3, first-session performance on these pairs was lower for Group A- than for Group $\mathrm{A}^{+}$, although not significantly so $[F(1,6)=$ 1.12].

Because of rapid learning of the stimulus pairs and the 3 days of minimum training on each phase, most of the pigeons received exactly three sessions of training on each discrimination pair, and thus the two groups differed very little in the mean amount of training they received on each phase (mean sessions/phase $=3.0$ and 3.1 for Groups A+ and A-, respectively).

\section{Test}

The BD test was performed with nondifferential reinforcement of choices of Stimuli B and D to avoid differential learning about the stimuli during the test. Because nondifferential reinforcement tends to reduce differences in initial performance across trials, the pigeons' choices on the first 24 trials of the test were examined. The mean percentage of trials on which the pigeons chose the predicted stimulus (i.e., B for Group A+ and $D$ for Group $A-$ ) was $89.6 \%$ for Group $A+$ and $85.4 \%$ for Group A-. This preference did not differ significantly for the two groups $[t(6)=1.41]$, but the performance of the two groups did differ significantly from chance $[50 \% ; t(7)=28.77]$.

It is difficult to make precise predictions of stimulus preferences on test trials on the basis of models of reinforcement history, because these models require the estimation of parameter values and depend somewhat on the precise sequence of reinforced and nonreinforced responses (see Couvillon \& Bitterman, 1992; Wynne et al., 1992). It should be the case, however, that the degree of preference for the B stimulus should depend on the relative number of reinforced and nonreinforced responses to the B and D stimuli. That is, one should expect to find a positive correlation between preference for $B$ and (1) relative number of reinforced responses to $B+$ versus $D+$, as well as (2) relative number of nonreinforced responses to D- versus B-. Inconsistent with predictions made by the reinforcement-history hypothesis, the correlation between the difference in reinforced responding between $\mathrm{B}+$ and $\mathrm{D}+$ during training and the preference for $B$ versus $D$ in test was negative rather than positive (Pearson's $r=-.28$ ). Similarly, the correlation between the difference in nonreinforced responding between $\mathrm{D}-$ and $\mathrm{B}-$ during training and the preference for B versus D in test was negative (Pearson's $r=-.60$ ). One could argue that the effect of a difference in reinforced or nonreinforced responses might depend on the overall number of such events in the presence of the two stimuli. For this reason, the correlational analyses were rerun using difference scores divided by the sum of reinforced responses to both $\mathrm{B}+$ and $\mathrm{D}+$. The resulting 
correlation coefficients were quite similar to those found by using simple difference scores (Pearson's $r=-.23$ and -.61 , respectively). Thus, the reinforcement-history account of the TI effect does not appear to account for the data.

The procedure used in Experiment 1, in which the stimulus pairs were trained successively, resulted in performance comparable to that found by Fersen et al. (1991, Experiment $1 ; 87.5 \%$ ), but with less attrition (all the pigeons learned) and a shorter training period (21-22 sessions). Thus, this successive training procedure may be useful for identifying the processes underlying successful TI task performance.

In Experiment 1, training involved three stimulus pairs $(\mathrm{AC}, \mathrm{CE}, \mathrm{AE})$ in addition to the four basic stimulus pairs that typically define TI training $(A B, B C, C D$, $D E)$. Training with these additional stimulus pairs may have provided the pigeons with examples of the transitive relation (e.g., if $\mathrm{A}+\mathrm{B}-$ and $\mathrm{B}+\mathrm{C}-$, then $\mathrm{A}+\mathrm{C}-$ ) necessary to obtain the results found with this blockedtrial procedure. On the other hand, additional exposures to Stimuli A, C, and E may have altered the values of those stimuli and thus may have altered the values transferred to the B and D test stimuli.

In addition, the pigeons used in Experiment 1 had also served earlier in a pilot study involving stimulus pairs and training related to the training received in Experiment 1 . To what extent was this earlier training instrumental in the observed transfer effect?

Experiment 2 was designed to determine if the rapid acquisition and successful test performance found in Experiment 1 could be obtained with pigeons that had had no prior simple discrimination training and that were trained with only the four basic stimulus pairs $(\mathrm{AB}, \mathrm{BC}$, $\mathrm{CD}$, and $\mathrm{DE}$ ).

\section{EXPERIMENT 2}

\section{Method}

\section{Subjects}

Eight mixed-sex White Carneaux pigeons were obtained and housed as in Experiment 1. Four of these pigeons had previously served as subjects in studies involving the delayed matching-tosample task; however, they had had no experience with simple discriminations or use of transitivity relations. The remaining $4 \mathrm{pi}-$ geons were experimentally naive. Experience was balanced across conditions.

\section{Apparatus}

The apparatus was the same as that used in Experiment 1.

\section{Procedure}

Pretraining. The experimentally naive pigeons were magazine trained, and then the keypeck response was shaped by the method of successive approximations. Following shaping, they were given pretraining that was the same as that for the experienced pigeons. In the first pretraining session, with the houselight illuminated, each pigeon was given experience with the five stimuli to be used in the experiment (red, yellow, white, blue, green). Each stimulus was presented individually, twice each on the center and right keys. When the subject made a single response, the stimulus was terminated and reinforcement was delivered. Following a $10-\mathrm{sec}$
ITI, the next stimulus was presented (order and position were randomly determined). The second session was the same as the first, except that the houselight was illuminated only during the ITI. In the third pretraining session, the number of responses required to produce reinforcement and the illuminated ITI was increased to five.

Training. Two experimentally naive and 2 experienced pigeons were randomly assigned to each group $(\mathrm{A}+$ and $\mathrm{A}-$ ). Training was the same as that in Experiment 1, except that only the four basic stimulus pairs $(\mathrm{AB}, \mathrm{BC}, \mathrm{CD}$, and $\mathrm{DE})$ were presented.

Test. The test was the same as that in Experiment 1.

\section{Results and Discussion}

\section{Training}

Sessions-to-criterion scores in Experiment 2 did not appear to be affected by prior experience or phase of training, and unlike the results of Experiment 1, these scores were not affected by group (see Table 2). A threeway mixed ANOVA was performed on sessions-tocriterion scores, with experience (experimentally naive vs. nonnaive), group (A+ vs. A-), and phase $(1-4)$ as factors. The analysis indicated no significant effects of experience [mean sessions to criterion $=2.7$ and 3.2 for experimentally naive and nonnaive pigeons, respectively; $F(1,4)=7.36]$, group $[M s=2.9$ and 3.1 for Groups $\mathrm{A}+$ and $\mathrm{A}-$, respectively; $F<1]$, or phase $[M \mathrm{~s}=2.8$, 3.0, 3.2, and 2.9 for Phases $1-4$, respectively; $F(1,4)=$ 1.06]. There were also no significant interactions.

Performance on the first session of each phase, however, did differ as a function of experience. These data, presented separately for each group, appear in Table 3 . The experimentally naive subjects (mean performance $=$ $79.1 \%$ ) performed at a significantly higher level than did the nonnaive subjects $[M=66.0 \% ; F(1,4)=8.81]$. The lower level of performance by the nonnaive subjects may have resulted from stimulus preferences produced by prior experience. Whatever the basis of the difference in performance on the first day of each training phase, the difference dissipated quickly and did not lead to significant differences in sessions-to-criterion scores. Although there was no significant effect of group [mean performance $=76.9 \%$ and $68.2 \%$ for Groups $\mathrm{A}+$ and $\mathrm{A}-$, respectively; $F(1,4)=3.90$ ], performance on the first session of each phase did differ significantly among phases [mean performance $=81.4 \%, 67.1 \%, 75.4 \%$, and $66.2 \%$ for Phases $1-4$, respectively; $F(3,12)=5.62$ ]. In addition, phase did not interact with either experience or group, indicating that the introduction of new phases did not differentially affect pigeons as a function of the level of the pigeons' experience or the group (A+vs. $\mathrm{A}-$ ).

\section{Test}

Mean test performance (percent choice of Stimulus B for Group A+ and Stimulus D for Group A-) on the first 24 test trials $(84.9 \%)$ was significantly higher than chance $[50 \% ; t(14)=11.45]$. This result indicates that training on the additional premise pairs that were presented in Experiment 1 is not necessary for successful test performance. It is possible that the training with additional stimulus pairs may have been helpful (mean test performance in Experiment $1=89.6 \%$, compared with 
$84.9 \%$ in Experiment 2); however, the differences in performance were small, and other differences between the two experiments do not allow for a meaningful statistical comparison of the data.

Test performance did not differ significantly as a function of experience (mean performance $=86.4 \%$ and $83.3 \%$ for experimentally naive and nonnaive subjects, respectively; $F<1$ ) or group (mean performance $=$ $82.3 \%$ and $87.5 \%$ for Groups $\mathrm{A}+$ and $\mathrm{A}-$, respectively; $F<1$ ). Again, the group $\times$ experience interaction was not significant $[F(1,4)=1.27]$.

Evidence of successful TI test performance can thus be demonstrated with a procedure that involves considerably less training than that used by Fersen et al. (1991) and that requires fewer discriminations than that used by Davis (1992b). Fersen et al. (1991) explained their TI findings by proposing that, in learning a simple discrimination (e.g., A+B-), the negative stimulus (B) acquires some positive value from its association with the positive stimulus (A). Stimulus D also acquires some positive value through its association with $\mathrm{C}+$, but whereas A never has its value diminished by nonreinforced responding, the value of $\mathrm{C}$ has been reduced by nonreinforced responding (in the presence of $\mathrm{B}+$ ). Thus, in this case, more value should transfer from Stimulus $A$ to Stimulus B than from Stimulus C to Stimulus D.

As mentioned earlier, differential reinforcement history associated with the two test stimuli has been proposed to account for findings of TI such as those found here (Couvillon \& Bitterman, 1992; Wynne et al., 1992). To explore this possibility, the data from Experiment 2 were subjected to a correlational analysis similar to that performed on the data from Experiment 1. Once again, the correlation between preference for $\mathrm{B}$ and differences in reinforced responding between $\mathrm{B}+$ and $\mathrm{D}+$ as well as differences in nonreinforced responding between $\mathrm{D}-$ and $\mathrm{B}-$ were negative (Pearson's $r=-.93$ and -.57 , respectively). Thus, once again, the correlations were in a direction opposite to that predicted by the reinforcementhistory hypothesis.

\section{EXPERMMENT 3}

The purpose of Experiment 3 was to provide a direct test of VTT by training pigeons with a series of simple simultaneous discriminations that should establish differential transferred value to two test stimuli without also establishing a transitive relation between them. As with the TI task used in Experiment 2, for one group, stimulus pairs were arranged so that one of the test stimuli (B) was experienced as an $\mathrm{S}$ - together with a stimulus that was always positive in value $(\mathrm{A}+)$. The other test stimulus (D) was experienced as an $\mathrm{S}$ - with a stimulus that was sometimes positive (i.e., positive in one pair), and sometimes negative (i.e., negative in another pair). However, whereas during training in Experiment 2 the test stimuli were both presented with a stimulus, C, that could mediate the relation between them, no such mediator was provided in Experiment 3. The pairings used were $\mathrm{A}+\mathrm{B}-, \mathrm{E}+\mathrm{C}-, \mathrm{C}+\mathrm{D}-$, and $\mathrm{A}+\mathrm{E}-$. The arrays produced by these pairings may be expressed as $A>$ $B$ and $A>E>C>D$. Although both $B$ and $D$ are less than $\mathrm{A}$, there is no mediator available to position $\mathrm{B}$ within the longer array. Therefore, it is impossible to determine the position of $B$ relative to $D$ by means of transitive ordering. However, if test stimuli obtain secondary value from their association with the other member of the stimulus pair in which they appear, then the overall value transferred to $D$ should be less than that transferred to B, and Stimulus B should be chosen over D in a nondifferential BD test. On the other hand, if the transfer effects found in TI experiments are produced only by the formation of a transitive relation among the training stimuli, then transfer effects similar to those found in Experiments 1 and 2 should not be found in Experiment 3.

\section{Method}

\section{Subjects}

Eight mixed-sex White Carneaux pigeons, similar in characteristics to those used in Experiment 2, were used. As in Experiment 2, 4 pigeons had had experience on an unrelated task, and 4 were experimentally naive. Experience was balanced across conditions.

\section{Apparatus}

The apparatus was the same as that used in Experiments 1 and 2.

\section{Procedure}

Pretraining. The pigeons received the same pretraining as that used in Experiment 2.

Training. Training was the same as that in Experiment 2, except that the four stimulus pairs used were drawn from a nonlinearly ordered array (Group $\mathrm{A}+\mathrm{A}+\mathrm{B}-, \mathrm{C}-\mathrm{E}+, \mathrm{C}+\mathrm{D}-, \mathrm{A}+\mathrm{E}-$; Group $\mathrm{A}-$ : $\mathrm{A}-\mathrm{B}+, \mathrm{C}+\mathrm{E}-, \mathrm{C}-\mathrm{D}+, \mathrm{A}-\mathrm{E}+$ ). In Experiment 3, the letters assigned to stimuli correspond to the stimuli used in Experiments 1 and 2, but no linear ordering is possible. Because Stimulus B was never presented with Stimulus $C$, no transitive relation should have developed between Stimulus B and Stimulus D.

Test. The test session involving the BD pair was the same as that in Experiments 1 and 2.

\section{Results and Discussion}

\section{Training}

Sessions-to-criterion scores suggested that there were differences in acquisition over the phases of the experiment (see Table 2). A three-way ANOVA performed on the data confirmed that there was a significant effect of phase $[F(3,12)=7.78]$, but there were no significant effects of experience $[F(1,4)=2.67]$ or group $(F<1)$. None of the interactions were significant.

Performance on the first session of each of the training phases, presented for each training group, appear in Table 3. A three-way ANOVA performed on the data from the first day of training on each discrimination indicated that performance did not differ significantly as a function of prior experience $[71.0 \%$ and $74.6 \%$ correct for experimentally naive and nonnaive pigeons, respectively; $F(1,4)=2.67]$ or group $(73.3 \%$ and $72.2 \%$ correct for Groups A+ and A-, respectively; $F<1$ ). Firstsession performance did differ significantly among phases $[76.0 \%, 86.6 \%, 30.4 \%$, and $98.1 \%$ correct for 
Phases $1-4$, respectively; $F(3,12)=21.04]$; however, none of the interactions among factors were significant.

\section{Test}

Choice of the stimulus predicted to be of a higher value by VTT (Stimulus B for Group A+, Stimulus D for Group A-) on the first 24 test trials was $92.7 \%$, which was significantly higher than chance $[50 \% ; t(14)=$ 11.92]. There were no significant differences in test performance as a function of experience [98.9\% and $86.5 \%$ correct for experimentally naive and nonnaive pigeons, respectively; $F(1,4)=3.12$ ] or group $(93.8 \%$ and $91.7 \%$ correct for Groups A+ and A-, respectively; $F<1$ ), and there was no significant group $X$ experience interaction $[F(1,4)=1.25]$.

The results of Experiment 3 indicate that, in a simple simultaneous discrimination, a stimulus associated with reinforced responding ( $\mathrm{S}+$ ) may transfer some of its value to a stimulus associated with nonreinforced responding $(\mathrm{S}-)$. These results are consistent with the hypothesis that the mechanism underlying the transfer effects found in Experiments 1 and 2, as well as those found in other TI experiments, may have been value transfer rather than the establishment of a transitive relation among stimuli. Although the transfer of stimulus value is sufficient to account for successful transfer performance in TI tasks, it does not rule out the possibility that a transitive relation was established among the stimuli in those experiments and that the transfer effects found in those experiments were multiply determined.

Recently, more direct support for VTT has been reported by Zentall and Sherburne (1994). In their experiments, pigeons were trained on two simultaneous discriminations, $\mathrm{A}+\mathrm{B}-$ and $\mathrm{C} \pm \mathrm{D}-$. Responses to $\mathrm{C} \pm$ were reinforced on only half of the trials and responses to $D$ were never reinforced. When the pigeons were then given a choice between $\mathrm{B}$ and $\mathrm{D}$, they showed a strong preference for $B$.

\section{GENERAL DISCUSSION}

The results of the present experiments have certain methodological implications. First, they indicate that TI effects can be found in pigeons when training involves blocked (successive) experience with each of the training pairs. Second, they indicate that when blocked experience is provided, it is not necessary to provide additional experience with some of the nonadjacent stimulus pairs (i.e., $\mathrm{AC}, \mathrm{CE}$, and $\mathrm{AE}$ ), as suggested by Davis (1992b).

The present results also have theoretical implications for findings of TI in animals. It is quite unlikely that a linear-operator model involving differences in reinforced and nonreinforced responding during training can account for the preferences found in test. Furthermore, the absence of a correlation between test performance and relative experiences with either reinforcement or nonreinforcement presents serious problems for all linear-operator theories.

Finally, the results of Experiment 3 suggest that stimulus preference can occur under conditions in which a relational theory cannot account for such a preference, but value transfer theory can. The fact that support for VTT can be demonstrated in the absence of an explanation in terms of relational learning does not rule out the possibility that some relational learning occurs in a typical TI task. A better test for the presence of relational learning would involve an experiment in which relational learning, but not VTT, could account for transfer effects.

\section{REFERENCES}

Bryant, P. E., \& Trabasso, T. (1971). Transitive inferences and memory in young children. Nature, $232,456-458$.

Chalmers, M., \& MCGonigle, B. O. (1984). Are children any more logical than monkeys on the five-term series problem? Journal of Experimental Child Psychology, 37, 355-377.

Couvillon, P. A., \& Bitterman, M. E. (1992). A conventional conditioning analysis of "transitive inference" in pigeons. Journal of Experimental Psychology: Animal Behavior Processes, 18, 308-310.

DAvIs, H. (1992a). Logical transitivity in animals. In W. K. Honig \& J. G. Fetterman (Eds.), Cognitive aspects of stimulus control (pp. 405 429). Hillsdale, NJ: Erlbaum.

DAVIS, H. (1992b). Transitive inference in rats (Rattus norvegicus). Journal of Comparative Psychology, 106, 342-349.

Fersen, L. von, Wynne, C. D. L., Delius, J. D., \& Staddon, J. E. R. (1991). Transitive inference formation in pigeons. Journal of Experimental Psychology: Animal Behavior Processes, 17, 334-341.

GiLlaN, D. J. (1981). Reasoning in the chimpanzee: II. Transitive inference. Journal of Experimental Psychology: Animal Behavior Processes, 7, 150-164.

MCGonigle, B. O., \& Chalmers, M. (1977). Are monkeys logical? Nature, 267, 694-696.

PIAGET, J. (1928). Judgment and reasoning in the child. London: Kegan Paul, Trench, \& Trubner.

PIAGET, J. (1955). The child's construction of reality. London: Routeledge \& Kegan Paul.

Trabasso, T., \& Rit.eY. C. A. (1975). The construction and use of representations involving linear order. In R. L. Solso (Ed.), Information processing and cognition: The Loyola Symposium (pp. 381-410). Hillsdale, NJ: Erlbaum.

Wynne, C. D. L., Fersen, L. von, \& Staddon, J. E. R. (1992). Pigeons' inferences are transitive and the outcome of elementary conditioning principles: A response. Journal of Experimental Psychology: Animal Behavior Processes, 18, 313-315.

Zentall, T. R., \& Sherburne, L. M. (1994). Transfer of value from $\mathrm{S}+$ to $\mathrm{S}-$ in a simultaneous discrimination. Journal of Experimental Psychology: Animal Behavior Processes, 20, 1-8.

(Manuscript received October 19, 1993; revision accepted for publication May 7, 1994.) 